\title{
Efficacy of hypnosis/guided imagery in fibromyalgia syndrome - a systematic review and meta-analysis of controlled trials
}

\author{
Kathrin Bernardy ${ }^{1}$, Nicole Füber ${ }^{2}$, Petra Klose ${ }^{3}$ and Winfried Häuser ${ }^{4,5^{*}}$
}

\begin{abstract}
Background: Recent systematic reviews on psychological therapies of fibromyalgia syndrome (FMS) did not consider hypnosis/guided imagery $(\mathrm{H} / \mathrm{Gl})$. Therefore we performed a systematic review with meta-analysis of the efficacy of $\mathrm{H} / \mathrm{Gl}$ in FMS.

Methods: We screened http://ClinicalTrials.gov, Cochrane Library, MEDLINE, PsycINFO and SCOPUS (through December 2010). (Quasi-) randomized controlled trials (CTs) comparing H/Gl with controls were analyzed. Outcomes were pain, sleep, fatigue, depressed mood and health-related quality of life (HRQOL). Effects were summarized using standardized mean differences (SMD).
\end{abstract}

Results: Six CTs with 239 subjects with a median of 9 (range 7-12) H/Gl-sessions were analysed. The median number of patients in the $\mathrm{H} / \mathrm{Gl}$ groups was 20 (range 8-26). Three studies performed follow-ups. $\mathrm{H} / \mathrm{Gl}$ reduced pain compared to controls at final treatment (SMD -1.17 [95\% Cl -2.21, -0.13]; $\mathrm{p}=0.03)$. H/Gl did not reduce limitations of HRQOL at final treatment (SMD $-0.90[95 \% \mathrm{Cl}-2.55,0.76] ; \mathrm{p}=0.29)$ compared to controls. Effect sizes on fatigue, sleep and depressed mood at final treatment and follow-up and on pain and HRQOL at follow-up were not calculated because of limited data available. The significant effect on pain at final treatment was associated with low methodological and low treatment quality.

Conclusion: Further studies with better treatment quality and adequate methodological quality assessing all key domains of FMS are necessary to clarify the efficacy of $H / G l$ in FMS.

\section{Background}

The key symptoms of fibromyalgia syndrome (FMS) are chronic widespread pain, fatigue (physical exhaustion and cognitive disturbances) and non-restorative sleep [1]. Besides these symptoms global multidimensional function ( $=$ health related quality of life [HRQOL]) and tenderness are regarded to be the key domains of therapeutic trials in FMS [2].

Patients with FMS use a lot of pharmacological and non-pharmacological therapies resulting in high costs of health services [3]. Pharmacological and physical therapies are more frequently used than psychological treatments. Although hypnotic pain relief is among the oldest treatments for pain, interest in hypnotic

\footnotetext{
* Correspondence: whaeuser@klinikum-saarbruecken.de

${ }^{4}$ Department of Internal Medicine I, Klinikum Saarbrücken, Winterberg 1, D66119 Saarbrücken, Germany

Full list of author information is available at the end of the article
}

treatments for chronic pain appears to rise only in the last decade [4]. In an internet survey only $3 \%$ of the respondents reported to use hypnosis to relieve FMSsymptoms [5].

A hypnotic procedure is used to encourage and evaluate responses to suggestions. When using hypnosis, one person (the subject) is guided by another (the hypnotist) to respond to suggestions [6]. The suggestions can be direct (traditional hypnosis) or permissive (Ericksonian hypnosis). Imagery is defined as a dynamic, psychophysiologic process in which a person imagines and experiences an internal reality in the absence of external stimuli. These images can be initiated by the patient or guided by a therapist (guided imagery) [7]. Both techniques aim to promote changes in subjective experience, alterations in perception, sensation, emotion, thought or behaviour by suggestion and/or imagination $[6,7]$.

\section{Biomed Central}


A recent qualitative review on hypnosis in chronic pain syndromes included only one study with hypnosis in FMS [8]. A recent systematic review on the efficacy of psychological therapies in FMS did not include studies with hypnosis/guided imagery [9]. Therefore we saw the need to perform a systematic review with metaanalysis of the efficacy of hypnosis/guided imagery compared to control therapies to reduce the key symptoms of FMS-patients of any age.

\section{Methods}

The review was performed according to the PRISMAstatement (Preferred Reporting Items for Systematic Reviews and Meta-Analyses [10] and the recommendations of the Cochrane Collaboration [11].

\section{Protocol}

Methods of analysis and inclusion criteria were specified in advance. We used the review protocol of our systematic review on cognitive behavioral therapies in FMS [12].

\section{Eligibility criteria \\ Types of interventions}

Studies with hypnosis and guided imagery as an active treatment of primary interest for FMS were included. Hypnosis/guided imagery should use pain-related and/or pain- addressed suggestions and/or images. Studies with relaxation only (without trance induction or without the use of imagination) or with the combination of hypnosis with a defined pharmacological therapy as an active treatment of primary interest were excluded. Experimental studies (single session) with hypnosis/guided imagery were excluded.

\section{Types of studies}

A controlled design (controlled trials $=$ CTs) was demanded. In case of multiple control groups we predefined the following order for comparison: Cognitive intervention (nonspecific elements of hypnosis/guided imagery such as education, emotional support, pure relaxation, suggestions without induction of hypnotic trance), treatment as usual, waiting list, active therapy (any defined pharmacological or non-pharmacological intervention other than hypnosis/guided imagery). The number of patients in each study arm should be $>5$. The studies should be available as a full publication in a peer reviewed science journal.

\section{Types of participants}

Patients diagnosed with FMS based on defined criteria and of any age were included.

\section{Types of outcomes measures}

Studies should assess at least one key domain of FMS (pain, sleep, fatigue, HRQOL) [2]. Depressed mood was chosen for secondary outcome because depressive symptoms frequently occur in FMS-patients [1] and improving emotional status is one main target of hypnosis/guided imagery [6,7].

\section{Data sources and searches}

The electronic bibliographic databases screened included http://ClinicalTrials.gov, Cochrane Central Register of Controlled Trials (CENTRAL), MEDLINE, PsycINFO and SCOPUS (through December 30, 2010). The search strategy for MEDLINE was as follows: (("Hypnosis"[Mesh] OR "Imagery (Psychotherapy)"[Mesh])) AND "Fibromyalgia"[Mesh] AND ((clinical [Title/Abstract] AND trial[Title/Abstract]) OR clinical trials[MeSH Terms] OR clinical trial[Publication Type] OR random*[Title/Abstract] OR random allocation[MeSH Terms] OR therapeutic use[MeSH Subheading])

The search strategy was adapted for the other databases. No language restrictions were made. In addition, reference sections of original studies were screened manually.

\section{Study selection}

Two authors independently screened the titles and abstracts of potentially eligible studies identified by the search strategy detailed above (NF, PK). The full text articles were then examined independently by two authors to determine if they met the inclusion criteria (KB, WH).

\section{Data collection process}

Two authors independently extracted the data using standard extraction forms (KB, NF). Discrepancies were rechecked and consensus achieved by discussion. If needed a third author reviewed the data to reach a consensus (WH).

We contacted all trial authors for further details of their methodology. The requests were answered by four authors. Where means or standard deviations (SDs) were missing, attempts were made to obtain these data through contacting four trial authors. Additional data were provided by three authors. Where SDs were not available from trial authors, they were calculated from t-values, confidence intervals or standard errors, where reported in articles. If these data were not available, the SD was substituted by the mean of the SDs of studies available which used the same outcome scale [12].

\section{Data items}

The data of study setting, participants, inclusion and exclusion criteria, interventions, cotherapies, side effects reported and outcomes used for meta-analysis are listed in tables 1 and 2 . 
Table 1 Main characteristics of controlled studies with hypnosis/guided imagery in fibromyalgia syndrome

\begin{tabular}{|c|c|c|c|c|c|c|c|}
\hline $\begin{array}{l}\text { Author } \\
\text { Country Year } \\
\text { Setting } \\
\text { Referral } \\
\text { [Reference] } \\
\end{array}$ & $\begin{array}{l}\text { Mean } \\
\text { age } \\
\text { (years) } \\
\text { Women } \\
\% \\
\end{array}$ & Exclusion criteria & $\begin{array}{l}\text { Diagnosis } \\
\text { of FMS }\end{array}$ & $\begin{array}{l}\text { Total study population } \\
\text { Screened/randomized } \\
\text { N (\%) Total/ } \\
\text { Completing therapy N } \\
(\%)\end{array}$ & $\begin{array}{l}\text { Treatment } \\
\text { group Total/ } \\
\text { Completing } \\
\text { therapy } \mathrm{N}(\%)\end{array}$ & $\begin{array}{l}\text { Control } \\
\text { group Total/ } \\
\text { Completing } \\
\text { therapy N } \\
(\%) \\
\end{array}$ & $\begin{array}{l}\text { Outcomes } \\
\text { used for } \\
\text { metaanalysis }\end{array}$ \\
\hline $\begin{array}{l}\text { Alvarez } \\
2007 \\
\text { Mexico } \\
\text { University } \\
\text { Hospital } \\
\text { Rheumatology } \\
\text { clinics } \\
{[23]}\end{array}$ & $\begin{array}{l}44 \text { yrs } \\
100 \% \\
\text { women } \\
100 \% \\
\text { Mexican } \\
\text { mez- } \\
\text { stizos }\end{array}$ & $\begin{array}{l}\text { No other significant painful or } \\
\text { chronic comorbidities }\end{array}$ & $A C R$ & $\begin{array}{l}50 / 43 \\
(86) \\
43 / 11(26)\end{array}$ & $\begin{array}{l}20 / 7 * \\
(35)\end{array}$ & $\begin{array}{l}23 / 4^{*} \\
(17)\end{array}$ & $\begin{array}{l}\text { Pain VAS 0- } \\
100 * \\
\text { Fatigue NA } \\
\text { Sleep NA } \\
\text { Depressed } \\
\text { mood NA } \\
\text { HRQOL: FIQ } \\
\text { total * }\end{array}$ \\
\hline
\end{tabular}

\begin{tabular}{llllll}
\multicolumn{1}{c}{} & & No follow- \\
up
\end{tabular}

\begin{tabular}{lllll}
\hline Grøndhal & $23-54$ yrs & Organic diseases & Clinical & $18 / 16$ \\
2008 & $75 \%$ & Severe psychiatric disorder & diagnosis of & $(89)$ \\
Norway & women & chronic & \\
General & $100 \%$ & widespread & $16 / 12(75)$ \\
practice & white & pain &
\end{tabular}

No follow-up

8/7 8/5 (63) Pain NRS 1-7*

(88) (a)

(a)

Fatigue NRS

1-7* (a)

Sleep NA

Depressed

mood NRS 1-

$7 *$ (a)

HRQOL NA

1 year without control

\begin{tabular}{|c|c|c|c|c|c|c|c|}
\hline $\begin{array}{l}\text { Haanen } \\
1991 \\
\text { Netherlands } \\
\text { Rheumatology } \\
\text { department } \\
\text { regional } \\
\text { hospital } \\
\text { NR } \\
\text { [26] }\end{array}$ & $\begin{array}{l}45 \text { yrs } \\
95 \% \\
\text { women } \\
\text { NR }\end{array}$ & Organic diseases & $\begin{array}{l}\text { Smythe } \\
\text { Normal } \\
\text { blood test }\end{array}$ & $\begin{array}{l}\mathrm{NP} \\
40 / 37 \text { (93) }\end{array}$ & $\begin{array}{l}20 / 17 \\
(85)\end{array}$ & $20 / 20(100)$ & $\begin{array}{l}\text { Pain VAS 0- } \\
10^{* *} \\
\text { Sleep VAS 0- } \\
10^{* *} \\
\text { Fatigue VAS } \\
0-10^{* * *} \\
\text { Depressed } \\
\text { mood NA } \\
\text { HRQOL NA }\end{array}$ \\
\hline
\end{tabular}

\begin{tabular}{|c|c|c|c|c|c|c|c|}
\hline & & & & & & & 12 weeks \\
\hline $\begin{array}{l}\text { Menziers } \\
2006 \\
\text { USA } \\
\text { University } \\
\text { hospital } \\
\text { Physicians and } \\
\text { clinics } \\
\text { [27] }\end{array}$ & $\begin{array}{l}50 \text { yrs } \\
98 \% \\
\text { women } \\
90 \% \\
\text { white }\end{array}$ & $\begin{array}{l}\text { Inflammatory rheumatic } \\
\text { disease } \\
\text { Major communicative disorder }\end{array}$ & $\begin{array}{l}\text { Clinical } \\
\text { diagnosis } \\
\text { Age }>18 \\
\text { FlQ-Total > } \\
20 \\
\text { MMSE score } \\
>25\end{array}$ & $\begin{array}{l}\mathrm{NP} \\
48 / \mathrm{NP}\end{array}$ & $24 / N R$ & $24 / \mathrm{NR}$ & $\begin{array}{l}\text { Pain VAS 0- } \\
10 \\
\text { Fatigue: NA } \\
\text { Sleep NA } \\
\text { Depressed } \\
\text { mood NA } \\
\text { HRQOL FIQ } \\
\text { total }\end{array}$ \\
\hline & & & & & & & 4 weeks \\
\hline
\end{tabular}


Table 1 Main characteristics of controlled studies with hypnosis/guided imagery in fibromyalgia syndrome (Continued)

\begin{tabular}{|c|c|c|c|c|c|c|c|}
\hline $\begin{array}{l}\text { Rucco } \\
1995 \\
\text { Italy } \\
\text { Regional } \\
\text { hospital } \\
\text { [28] }\end{array}$ & $\begin{array}{l}38 \text { yrs } \\
100 \% \\
\text { women } \\
\text { NR }\end{array}$ & $\begin{array}{l}\text { Analgesic medication } \\
\text { Major psychiatric disorder }\end{array}$ & $\begin{array}{l}\text { ACR criteria } \\
\text { Normal } \\
\text { blood tests }\end{array}$ & $\begin{array}{l}N P \\
53 / 35(66)\end{array}$ & $\begin{array}{l}26 / 24 \\
(92)\end{array}$ & $\begin{array}{l}27 / 11 \\
(41)\end{array}$ & $\begin{array}{l}\text { Pain VAS 0- } \\
10 \\
\text { Fatigue NA } \\
\text { Sleep VAS 0- } \\
10 \\
\text { Depressed } \\
\text { mood NA } \\
\text { HRQOL NA }\end{array}$ \\
\hline
\end{tabular}

\footnotetext{
Abbreviations: * Data provided on request; (a) adjusted for baseline values; ** Median used for analysis; Standard deviation not reported; calculated from mean of other trials; ${ }^{* *}$ Median not entered into meta-analysis; no calculation of standard deviation from other trials possible

$\mathrm{FIQ}=$ Fibromyalgia Impact questionnaire; $\mathrm{HRQOL}=$ Health-related quality of life; NA = Not assessed; NP = Not provided on request; NRS = Numeric Rating Scale; VAS = Visual Analogue Scale;
}

\section{Risk of bias in individual studies and quality ratings}

To ascertain the methodological quality of the eligible studies, two authors independently (KB, NF) rated eligible trials using a scale developed specifically for assessing the quality of psychological treatments for chronic pain [13]. Discrepancies were rechecked and consensus achieved by discussion. If needed a third author reviewed the data to reach a consensus (WH). The Quality Rating Scale is comprised of an overall quality score (0-35) consisting of two subscales. A treatment quality subscale (09) covers stated rationale for treatment, manualization, therapist training and patient engagement. Patient engagement was defined by checking for trance phenomena during hypnosis and/or execution of homework audiotape training. A design and methods quality subscale (0-26) covers inclusion/exclusion criteria, attrition, sample description, minimization of bias (randomisation method, allocation bias, blinding of assessment, equality for treatment expectations), selection of outcomes, length of follow-up, adequacy of statistical analyses (a priori power calculation, sufficient sample size, adequate data analysis and summary statistics, intention to treat analysis) and choice of control. We assumed a sample size of at least 10 per treatment arm to be sufficient. We defined scores $0-2$ to indicate a poor, scores 3-5 an average and scores 6-9 an excellent treatment quality and scores 0-12 indicating a low, scores 13-19 a medium and scores $>19$ a high methodological quality. Interrater reliability was calculated for both subscales by intra-class correlation coefficients (ICC).

\section{Summary measures}

Meta-analyses were conducted using RevMan Analyses software (RevMan 5.0.24) of the Cochrane collaboration [14]. Standardized mean differences (SMD) were calculated by means and SDs for each intervention. Examination of the combined results was performed by a random effects model (inverse variance method), because this model is more conservative than the fixedeffects model and incorporates both within-study and between-study variance [15]. SMD used in Cochrane reviews is the effect size known as Hedges (adjusted) g. We used Cohen's categories to evaluate the magnitude of the effect size, calculated by SMD, with $g>0.2-0.5=$ small effect size, $\mathrm{g}>0.5-0.8=$ medium effect size, $\mathrm{g}>$ 0.8 = large effect size [16].

\section{Planned methods of analysis}

Heterogeneity was tested using the $\mathrm{I}^{2}$ statistics with $\mathrm{I}^{2}$ values above $50 \%$ indicate substantial heterogeneity. $\mathrm{Tau}^{2}$ was used to determine how much heterogeneity was explained by subgroup differences [11].

\section{Risk of bias across studies}

Potential publication bias (i.e. the association of publication probability with the statistical significance of study results) was investigated the Egger test, in which the standardized effect size (effect size calculated by standard error) is regressed on precision (inverse of standard error). The intercept value is an estimate of asymmetry of funnel plot. Positive values $(>0)$ indicate higher levels of effect size in studies with smaller sample sizes [17].

\section{Additional analyses}

\section{Subgroup and sensitivity analysis}

If there were at least three studies available, subgroup analyses were prespecified for type of psychological therapy (hypnosis and guided imagery; hypnosis/guided imagery with and without home training with audiotapes) and type of control group. These subgroup analyses were also used to examine potential sources of clinical heterogeneity.

We decided post-hoc to perform a sensitivity analysis of studies without calculated values (median instead of mean; SD calculated from other studies; adjusting for baseline values).

\section{Metaregression analyses}

We a priori decided to metaregress SMDs with the treatment and methodological quality score for potential sources of heterogeneity. We post - hoc decided to 
Table 2 Details on therapeutic techniques and co-therapies of the studies analysed

\begin{tabular}{|c|c|c|c|}
\hline $\begin{array}{l}\text { Author } \\
\text { (Reference) }\end{array}$ & $\begin{array}{l}\text { Types and duration of treatment in hypnosis/ } \\
\text { guided imagery group }\end{array}$ & Types and duration of treatment in controls & $\begin{array}{l}\text { Comedication allowed } \\
\text { Other cotherapies } \\
\text { Side effects reported }\end{array}$ \\
\hline Alvarez [23] & $\begin{array}{l}\text { Ericksonian hypnosis, individual: } \\
\text { Induction NR; } 5 \text { techniques could be used for } \\
\text { utilisation: transformation of pain or emotion; } \\
\text { metaphors; dissociation of pain; perceptions of other } \\
\text { body sensations; pleasant imagery; posthypnotic } \\
\text { suggestions of negative hallucinations and amnesia of } \\
\text { pain } \\
60 \text { min, } 6-8 \text { sessions over } 6 \text { months } \\
\text { Total: } 420 \text { min }\end{array}$ & $\begin{array}{l}\text { Cognitive intervention: Sham hypnosis, individual: } \\
\text { General issues talking with the therapist; physical } \\
\text { sign check list to verify that the patients were not in } \\
\text { hypnotic trance * } \\
60 \text { min, } 6-8 \text { sessions over } 6 \text { months } \\
\text { Total: } 420 \text { min }\end{array}$ & $\begin{array}{l}\text { NSAIDs, amitriptyline, } \\
\text { physiotherapy kept } \\
\text { stable during study * } \\
\text { NR } \\
4 / 20 \text { with hypnosis drop } \\
\text { out lack of efficacy } \\
7 / 20 \text { with sham } \\
\text { hypnosis drop out lack } \\
\text { of efficacy }\end{array}$ \\
\hline Castel [24] & $\begin{array}{l}\text { CBT plus standardised hypnosis; group: Induction by } \\
\text { fixation and palpepral catalepsy; deepening by } \\
\text { visualisation; suggestion of an analgesic stream } \\
\text { eliminating pain and creating feelings of well-being; } \\
\text { posthypnotic suggestions NR } \\
90 \text { min (of which } 20 \text { min hypnosis) for } 12 \text { weeks; } \\
\text { daily home training with audiocasettes recommended } \\
\text { Total: } 1080 \text { min }\end{array}$ & $\begin{array}{l}\text { Active control: CBT; group. Information in FMS, } \\
\text { cognitive restructuring, assertiveness training, } \\
\text { behavioral goal setting, problems solving; } \\
90 \text { min (of which } 20 \text { min relaxation training) for } 12 \\
\text { weeks } \\
\text { Total: } 1080 \text { min } \\
\text { Study arm treatment as usual not used for } \\
\text { comparison }\end{array}$ & $\begin{array}{l}\text { Analgesics, } \\
\text { antidepressants, } \\
\text { sedatives, myorelaxants } \\
\text { NR } \\
\text { NR }\end{array}$ \\
\hline $\begin{array}{l}\text { Grøndahl } \\
{[25]}\end{array}$ & $\begin{array}{l}\text { Standardised hypnosis, individual: Relaxation, } \\
\text { visualisation of positive body experience; suggestion } \\
\text { of increase of self-efficacy, posthypnotic suggestions } \\
\text { NR } \\
10 \text { wks, 1/week, } 30 \text { min } \\
\text { Total: } 300 \text { min }\end{array}$ & $\begin{array}{l}\text { Treatment as usual: Medication and physiotherapy or } \\
\text { chiropractic therapy } \\
\text { Total Min NR }\end{array}$ & $\begin{array}{l}\text { Medication and } \\
\text { physiotherapy or } \\
\text { chiropractic therapy } \\
\text { NR } \\
\text { NR }\end{array}$ \\
\hline $\begin{array}{l}\text { Haanen } \\
\text { [26] }\end{array}$ & $\begin{array}{l}\text { Standardised hypnosis, individual and daily } \\
\text { audiocassette: Induction by arm levitation; } \\
\text { suggestions of ego-strengthening, pain control and } \\
\text { improvement sleep; posthypnotic suggestions NR } \\
8 \times 60 \text { min over } 3 \text { months; daily home training } \\
\text { Total: } 360 \text { min (without home training) }\end{array}$ & $\begin{array}{l}\text { Active control } \\
\text { Physical therapy: Massage and muscle relaxation 1-2 } \\
\text { h/week over } 12 \text { weeks } \\
\text { Total: } 720-1440 \text { min }\end{array}$ & $\begin{array}{l}\text { Only paracetamol } \\
\text { allowed } \\
\text { NR } \\
\text { NR }\end{array}$ \\
\hline $\begin{array}{l}\text { Menziers } \\
{[27]}\end{array}$ & $\begin{array}{l}\text { Standardised guided imagery, indvidual, at home: } \\
3 \text { standardised audio cassettes: Relaxation, signal } \\
\text { breath to elicit relaxation; imagination of pleasant } \\
\text { scene; suggestions of feeling of well-being and } \\
\text { actions and behaviors free of FMS-symptoms } \\
30 \text { min daily for } 6 \text { weeks recommended } \\
\text { Total: Median of } 44 \text { (range 37-136) exercises }\end{array}$ & $\begin{array}{l}\text { Treatment as usual } \\
\text { Total Min NR }\end{array}$ & $\begin{array}{l}\text { Treatment as usual } \\
\text { NR } \\
\text { NR }\end{array}$ \\
\hline Rucco [28] & $\begin{array}{l}\text { Ericksonian hypnosis, individual: Metaphors for } \\
\text { induction, Utilisation: identification and solution of } \\
\text { intrapsychic conflicts; posthypnotic suggestions NR } \\
\text { Frequency of sessions individualised over } 6 \text { months }\end{array}$ & $\begin{array}{l}\text { Active control: Autogenic training in group } \\
\text { Practice: } 8 \text { weeks, twice a week, } 15 \text { min; } \\
\text { Recommendation of daily practice over } 6 \text { months } \\
\text { Total: } 240 \text { min }\end{array}$ & $\begin{array}{l}\text { No comedication } \\
\text { allowed } \\
\text { NR } \\
\text { NR }\end{array}$ \\
\hline
\end{tabular}

* Details provided on request; NR $=$ Not reported and not provided on request

metaregress SMDs with the number of the participants of the studies. Meta-regression was performed using the mixed effects model. Tau ${ }^{2}$ variance was calculated by the method of unrestricted maximum likelihood by Comprehensive Metaanalysis software [18].

\section{Results}

\section{Results of search}

The search of literature yielded 57 hits. After excluding studies based on information presented in study abstracts, nine complete study reports were considered 
in more detail. One double published study with experimental guided imagery $[19,20]$, one study with experimental hypnosis [21] and one study with two patients in each treatment arm [22] were excluded. Finally six studies were included in qualitative analysis [23-28] (see figure 1).

\section{Study characteristics}

\section{Setting, referral and exclusion criteria}

Four studies were conducted in Europe and one study each in USA and Mexico. Patients were recruited by registers of hospitals, referral (general practitioner, rheumatologist, departments of hospitals) and local self-help groups. Five studies were conducted in hospitals (university, district hospital) and one study in a general practitioner office. All studies were single center based. One study did not report the exclusion criteria. All other studies included only adult patients ( $>18$ years) and excluded patients with major somatic and/or mental diseases. One study excluded patients with litigation/ pension associated with FMS and one study excluded patients who were taken analgetisic medication (see table 1).

FMS was diagnosed in three studies by the criteria of the American College of Rheumatology [29], in one study by the Smythe criteria [30] and in two studies by clinical (not further specified) criteria. No study reported the frequency of mental disorders.

\section{Participants}

Two studies reported the percentage of persons screened who were subsequently randomised with a median of 87 (range 86-89) \%. The median of the mean age of the participants was 44 (range 38-50) years. The median of the percentage of women was 96 (range $75-100$ ) \%. Six studies reported the race of the patients. The median of the percentage of Caucasians was 95 (0-100) \%. One Mexican study included 100\% mestizos.

The median of the patients under hypnosis/guided imagery in the studies was 20 (range 8-26) and of controls was 22 (range 8-27) (see table 1). The total number of patients with hypnosis/guided imagery was 115 of which a median percentage of 88 (range 35-94) \% completed therapy. The total number of patients in the control groups was 124 of which a median percentage of 63 (range 17-100) completed therapy $(\mathrm{z}=-0.5, \mathrm{p}=$ $0.7)$.

\section{Interventions}

Five studies offered hypnosis: Three studies with direct hypnosis of which one was combined with cognitivebehavioral therapy, two studies with indirect [Ericksonian] hypnosis). One study offered guided imagery. Four studies with hypnosis explicetly mentioned the use of mental images. All but one study used suggestions and/ or images which were directly addressed to the pain experience. All studies used pain-related suggestions. The study with guided imagery used suggestions. Hypnosis/guided imagery were delivered in five studies as individual therapy and in one study as group therapy. Hypnosis/guided imagery were offered in five studies by face-to face (life), in one study by audiotapes. Three studies recommended daily training at home with audiotapes. The median number of sessions with a therapist was nine (range 7-12). The median of hypnosis/guided imagery delivered by a therapist was 390 (range 300$1080 \mathrm{~min}$ ). The number of sessions in one trial with Ericksonian hypnosis was individualized. Median and range of the number of sessions of this study were not reported.

In one study controls received a cognitive intervention (sham hypnosis), in three studies active therapy (cognitive behavioral therapy, physical therapy, autogenic training) and in two studies treatment as usual (see table 2).

Three studies performed a follow-up of which one (after one year) was without controls because the controls had switched to hypnotherapy. The median of follow-up of the other two studies was 8 (range 4-12) weeks.

\section{Outcomes}

Pain was assessed in all studies, sleep in two and fatigue and depressed mood in one study each by visual or numeric scales. HRQOL was assessed in three studies by the Fibromyalgia Impact Questionnaire. Two authors provided additional outcomes on request. One author did not provide the means and standard deviations of his study in which medians and ranges had been presented (see table 1).

No study assessed predefined response rates (e.g. percentage of patients with $30 \%$ pain reduction). Only one study reported the number of patients who dropped out because of lack of efficacy. No study reported on side effects.

\section{Quality ratings of trials}

Three authors provided additional information on methods on request (see tables 3 and 4). The ICC using absolute agreement for the two raters was $0.96(\mathrm{~F}=3.4)$ for the treatment quality and $0.97(\mathrm{~F}=3.4)$ for the design quality subscale.

The median of the treatment quality score was 6 (range 1-9). One study had a poor, two studies had a medium and three studies had an excellent treatment quality score (see table 3 ).

The median of the methodological quality score was 16 (range 10-20). One study had a poor, four studies had a medium and one study had an excellent methodological quality score (see table 4). 


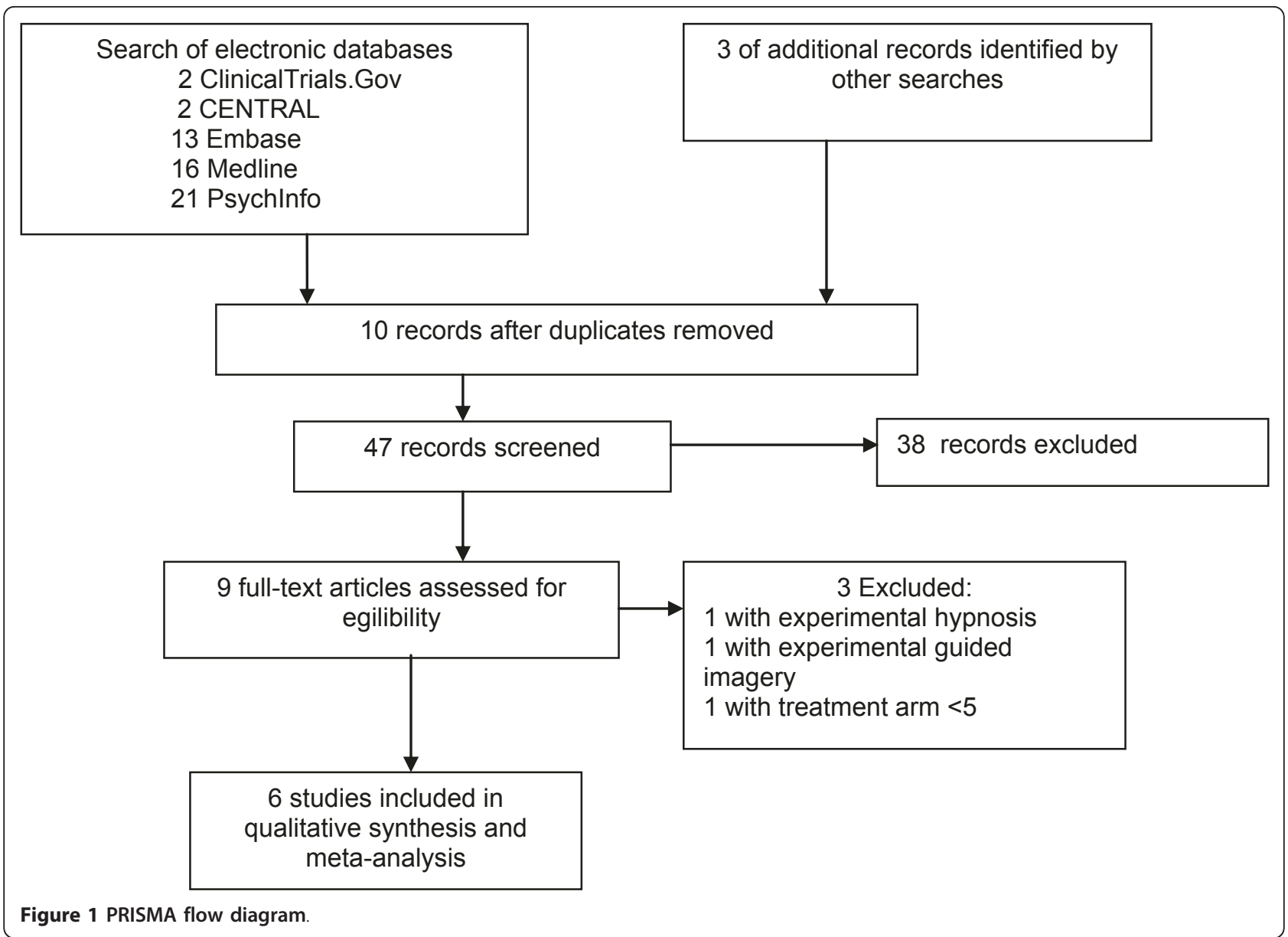

\section{Synthesis of results}

\section{Overall meta-analysis}

The means, SDs, sample sizes and effect estimates at posttreatment and at follow-up of the remaining eight studies can be seen in the forest plots (see figure 2).

The data are reported as follows: (SMD [95\% Confidence interval]). Hypnosis/guided imagery reduced pain $(-1.17[-2.21,-0.13])$ compared to controls at final treatment. Hypnosis/guided imagery did not reduce the limitations of HRQOL -0.90 [-2.55, 0.76] compared to controls at final treatment. Based on Cohens' categories the effect on pain at final treatment was large.

Because of limited data available effect sizes on sleep, fatigue and depressed mood were not calculated at final treatment and not for all outcomes at follow-up (see table 1). Two studies reported that hypnosis was superior to controls in reducing sleep disturbances at final treatment $[26,28]$. Two studies reported that hypnosis/ guided imagery was superior to controls in reducing pain at follow-up [26,27]. One study reported that hypnosis was superior to controls in reducing fatigue at final treatment and at follow-up [26]. In one study hypnosis was not superior to therapy as usual at posttreatment in reducing depressed mood [25].

\section{Potential publication bias}

In the Egger's test the intercept of the effect size on pain was $0.13(95 \% \mathrm{CI}-8.7,9.0)$ with $\mathrm{t}=0.03$ (two-tailed $\mathrm{p}=$ 0.97 ) and thus not indicative for a publication bias.

\section{Risk of bias across studies and subgroup analysis}

There was substantial heterogeneity in the outcome pain at final treatment (see table 5). Subgroup analyses were not calculated, because $<4$ studies for subgroups were available.

\section{Sensitivity analysis}

The effect on pain at final treatment was no more significant after removing the two studies in which some values were calculated by the authors of this review $\left(-1.38[-2.95,0.20] ; \mathrm{I}^{2}=92 \% ; \mathrm{p}=0.09\right)$.

\section{Metaregression analyses}

Simple linear regressions showed that treatment quality $(B=-3.6, p<0.0001)$, and methodological quality $(B=$ $-8.7, \mathrm{p}<0.0001)$ ) were significantly negatively associated with the effect size on pain at final treatment. Sample size was not associated with the effects size on pain at final treatment $(B=0.42, \mathrm{p}=0.65)$. 
Table 3 Treatment quality of studies with guided imagery/hypnosis in FMS

\begin{tabular}{llllllll}
\hline $\begin{array}{l}\text { Author } \\
\text { (Reference) }\end{array}$ & $\begin{array}{l}\text { Treatment } \\
\text { content }\end{array}$ & $\begin{array}{l}\text { Treat-ment } \\
\text { duration }\end{array}$ & $\begin{array}{l}\text { Manualisa-tion of } \\
\text { treatment }\end{array}$ & $\begin{array}{l}\text { Adherence to } \\
\text { manual }\end{array}$ & $\begin{array}{l}\text { Therapist } \\
\text { training }\end{array}$ & $\begin{array}{l}\text { Client } \\
\text { engagement }\end{array}$ \\
\hline Alvarez [23] & Adequate (2) & Reported (1) & Partial (1) ${ }^{*}$ & Partial (1) ${ }^{*}$ & Adequate $(2)^{*}$ & $\begin{array}{l}\text { Adequate }(1)^{*} \\
8\end{array}$ \\
\hline Castel [24] & Adequate (2) & Reported (1) & Partial (1) & Inadequate (0) & Inadequate (0) & Inadequate (0) & 4 \\
\hline Grøndahl [25] & Adequate (2) ${ }^{*}$ & Reported (1) & Adequate (2) ${ }^{*}$ & Partial (1) ${ }^{*}$ & Adequate (2) ${ }^{*}$ & Adequate (1) & 9 \\
\hline Haanen [26] & Adequate (2) & Reported (1) & Partial (1) & Inadequate (0) & Inadequate (0) & Inadequate (0) & 4 \\
\hline Menziers [27] & Adequate (2) & Reported (1) & Adequate (2) & Adequate (2) & Inadequate (0) & Adequate (1) & 8 \\
\hline Rucco [28] & Inadequate (0) & Not reported (0) & Inadequate (0) & Inadequate (0) & Inadequate (0) & Inadequate (0) & 0 \\
\hline
\end{tabular}

* Data provided on request

\section{Discussion}

\section{Summary of evidence}

The evidence of the efficacy of hypnosis/guided imagery to reduce pain at final treatment was not robust against risks of methodological bias and was associated with low methodological study quality.

\section{Applicability of evidence}

The study settings of all levels of care and the study samples with a preponderance of middle aged women are representative for clinical FMS populations in America and Europe.

\section{Agreements with other systematic reviews}

The German FMS guideline group concluded by a qualitative systematic review that hypnosis/guided imagery was superior to controls in reducing pain, sleep disturbances and fatigue [31]. Our update of the literature with inclusion of recently published studies and quantitative analysis of outcomes supports that hypnosis/guided imagery was effective in relieving pain and sleep problems. A meta-analytic confirmation of the efficacy on fatigue was not possible because of the methodological problems outlined above. In contrast to a recent qualitative review on psychological therapies in FMS which described "mild effects" of hypnosis/guided imagery on FMS-symptoms [32] we found large effects on pain and medium effects sizes on sleep at final treatment and at follow-up.

\section{Limitations}

We decided to pool studies with hypnosis and guided imagery because of their similaries regarding theoretical

Table 4 Methodological quality of studies with guided imagery/hypnosis in FMS

\begin{tabular}{|c|c|c|c|c|c|c|}
\hline Author (Reference) & Alvarez [23] & Castel [24] & Grøndhal [25] & Haa-nen [26] & Men-ziers [27] & Rucco [28] \\
\hline Sample criteria & Adequate (1) & Adequate (1) & Adequate (1) & Adequate (1) & Adequate (1) & Inadequate $(0)$ \\
\hline Evidence that sample criteria were met & Adequate (1) & Adequate (1) & Inadequate (0) & Adequate (1) & Adequate (1) & Inadequate $(0)$ \\
\hline Report of attrition & Adequate (2) & Partial (1) & Adequate (2) & Adequate (2) & Adequate (2) & Partial (1) \\
\hline Rates of attrition & Adequate (1) & Adequate (1) & Adequate (1) & Adequate (1) & Adequate (1) & Adequate (1) \\
\hline Sample characteristics & Adequate (1) & Adequate (1) & Inadequate (0) & Adequate (1) & Adequate (1) & Adequate (1) \\
\hline Group equivalence & Adequate (1) & Inadequate $(0)$ & Inadequate $(0)$ & Adequate (1) & Adequate (1) & Adequate (1) \\
\hline Adequacy of randomisation & Adequate $(2)^{*}$ & Inadequate (0) & Adequate $(2)^{*}$ & Inadequate (0) & Inadequate $(0)$ & Inadequate $(0)$ \\
\hline Concelament of treatment allocation & Adequate $(1)^{*}$ & Inadequate $(0)$ & Adequate $(1)^{*}$ & Inadequate $(0)$ & Inadequate $(0)$ & Inadequate (0) \\
\hline Blinding of assessor & Adequate $(1)^{*}$ & Inadequate (0) & Adequate $(1)^{*}$ & Inadequate (0) & Inadequate $(0)$ & Inadequate $(0)$ \\
\hline Treat-ment expectations & Inadequate $(0)$ & Inadequate $(0)$ & Inadequate $(0)$ & Inadequate $(0)$ & Inadequate $(0)$ & Inadequate (0) \\
\hline Justifications of outcomes & Adequate (1) & Adequate (1) & Adequate (1) & Adequate (1) & Adequate (1) & Adequate (1) \\
\hline Validity of outcomes for context & Adequate (2) & Adequate (2) & Adequate (2) & Adequate (2) & Adequate (2) & Adequate (2) \\
\hline Reliability and sensitivity to change of outcomes & Adequate (2) & Adequate (2) & Adequate (2) & Adequate (2) & Adequate (2) & Adequate (2) \\
\hline Follow up of at least 6 months & Inadequate $(0)$ & Inadequate $(0)$ & Inadequate (0) & Inadequate (0) & Inadequate $(0)$ & Inadequate $(0)$ \\
\hline Power calculation & Inadequate (0) & Inadequate $(0)$ & Inadequate $(0)$ & Inadequate (0) & Inadequate (0) & Inadequate $(0)$ \\
\hline$\underline{\text { Sufficient sample size }}$ & Inadequate $(0)$ & Adequate (1) & Inadequate (0) & Adequate (1) & Adequate (1) & Adequate (1) \\
\hline Adequate data analysis & Adequate (1) & Adequate (1) & Adequate (1) & Adequate (1) & Adequate (1) & Adequate (1) \\
\hline Adequate reporting of summary statistics & Adequate (1) & Adequate (1) & Adequate $(1)^{*}$ & Adequate (1) & Adequate (1) & Inadequate $(0)$ \\
\hline Intention to treat analysis & Inadequate (0) & Inadequate $(0)$ & Inadequate $(0)$ & Adequate (1) & Inadequate $(0)$ & Inadequate (0) \\
\hline Control group & Adequate (2) & Adequate (2) & Adequate (2) & Adequate (2) & Adequate (2) & Inadequate $(0)$ \\
\hline Sum & 20 & 14 & 17 & 17 & 16 & 10 \\
\hline
\end{tabular}

* Data provided on request 


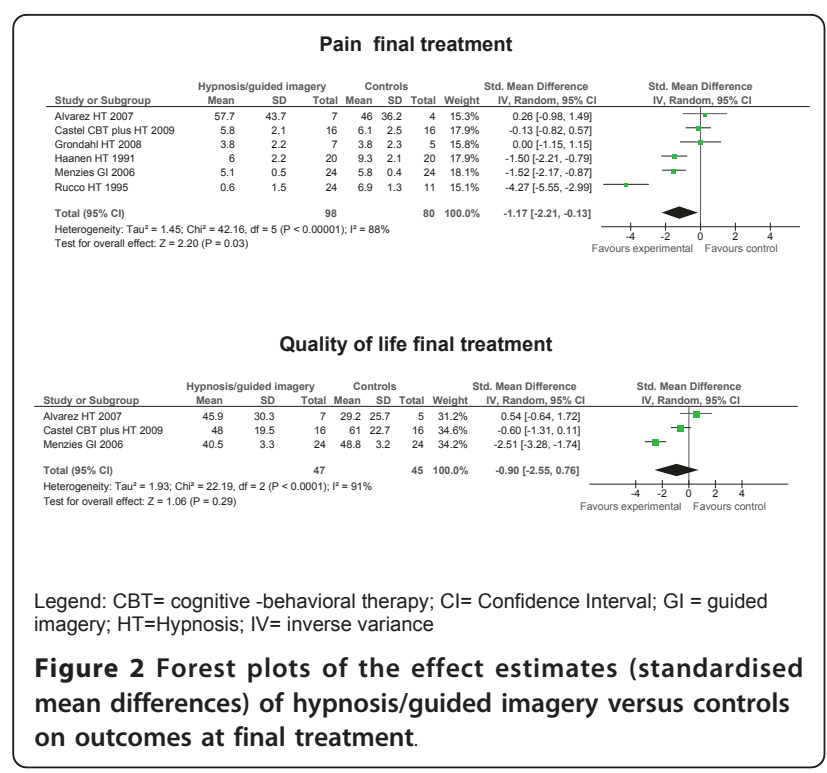

assumptions and therapeutic technics. But not all hypnosis involves guided imagery, and guided imagery does not necessarily result in a hypnotic state. The intended subgroup analysis of hynosis and guided imagery was not possible due to limited data.

In contrast to a recent Cochrane review on psychological therapies in chronic pain [33] we included studies with less than 10 participants in each study arm because of the limited number of studies with hypnosis/guided imagery available. Metaregression demonstrated no significant correlation between the magnitude of effect size on pain at final treatment and sample size. Thereforefore the positive effect on pain is robust against small sample size in our analysis.

Although every effort was made to obtain missing data on study design from authors, it was not possible in every case to obtain them. Therefore the study quality might be underestimated in some trials.

Some major risks of bias listed in Cochrane reviews (adequacy of randomisation, concealment of treatment allocation, blinding of the outcome assessor, ITT-analysis) [10] were present in the majority of studies. Metaregression analysis demonstrated that the positive effect on pain was associated with low methodological study quality.

We substituted one missing SD despite the small sample sizes and substantial heterogeneity. Furthermore we adjusted the outcomes posttreatment by baseline values because of baseline differences of one study. We demonstrated by sensitivity analyses that by removing these two studies only a statistical trend $(\mathrm{p}<0.1)$ of the effect of hypnosis/guided imagery on pain at final treatment was detectable.

There was significant between-study heterogeneity for the outcome pain. To address this limitation we used a random-effects model.

It should be emphasized that all analyses might be underpowered due to the limited number of studies.

Adverse events were not reported. Therefore no definitive statement on the safety of hypnosis/guided imagery in FMS is possible.

Responses in studies with chronic pain patients are frequently not Gaussian, but with a split between responders and non-responders. No study assessed

Table 5 Effect sizes of hypnosis/guided imagery on selected outcome variables

\begin{tabular}{|c|c|c|c|c|c|}
\hline Outcome title & $\begin{array}{l}\text { Number of } \\
\text { studies }\end{array}$ & $\begin{array}{l}\text { Number of } \\
\text { patients }\end{array}$ & $\begin{array}{l}\text { Effect size (SMD [95\% } \\
\text { CI]) }\end{array}$ & $\begin{array}{l}\text { Test for overall effect } p \text { - } \\
\text { value }\end{array}$ & $\begin{array}{l}\text { Heterogeneity } \mathrm{I}^{2}[\%] ; \\
\text { Tau }^{2}\end{array}$ \\
\hline \multicolumn{6}{|c|}{ Final treat-ment } \\
\hline 01 Pain & 6 & 178 & $-1.17[-2.21,-0.13]$ & 0.03 & $88 ; 1.45$ \\
\hline 02 Fatigue & 1 & 12 & Not calculated & & \\
\hline 03 Sleep & 2 & 66 & Not calculated & & \\
\hline $\begin{array}{l}\text { 04 Depressed } \\
\text { mood }\end{array}$ & 1 & 12 & Not calculated & & \\
\hline $05 \mathrm{HRQOL}$ & 3 & 92 & $-0.90[-2.55,0.76]$ & 0.29 & $91 ; 1.93$ \\
\hline \multicolumn{6}{|l|}{ Follow up } \\
\hline 01 Pain & 2 & 88 & Not calculated * & & \\
\hline 02 Fatigue & 1 & 40 & Not calculated & & \\
\hline 03 Sleep & 1 & 40 & Not calculated & & \\
\hline $\begin{array}{l}\text { 04 Depressed } \\
\text { mood }\end{array}$ & 0 & 0 & & & \\
\hline $05 \mathrm{HRQOL}$ & 1 & 48 & Not calculated & & \\
\hline
\end{tabular}

Abbreviations: HRQOL: Health-related quality of life; SMD: Standardised mean difference; Cl: Confidence interval

* Standard deviation of one study not available 
predefined response rates (e.g. 30\% pain reduction). Therefore IMMPACT response outcomes [34] could not be calculated.

\section{Conclusions}

Implications for clinical practice

Because of the methodological limitations of the studies with hypnosis/guided imagery outlined above we cannot fully recommend hypnosis/guided imagery for FMS therapy. The use of hypnosis/guided imagery as an adjunct to efficacious pharmacological and non-pharmacological treatments had been recommended by the German interdisciplinary guideline on FMS based on expert consensus [31]. Regular home training by audiotapes with hypnotic suggestions and guided imaginations could be useful.

\section{Implications for research}

Further studies with multi-site recruitment producing adequate sample sizes are necessary to allow for stronger tests of treatment efficacy and for examination of individual (e.g. gender, age, hypnotisability) differences in treatment response. Moreover the appropriate methods (live or audiotape therapy or combination of both types) and the optimal dosage need to be determined. Predictors of positive treatment outcomes, e.g. suggestibility and treatment expectations, should be explored [32].

The methodological quality of further studies could be improved by the following issues: The key domains of FMS should be assessed by a core set of outcome measures. Response rates should be measured [34]. Recommendations on the quality of the treatment delivered and study design should be followed [13].

\begin{abstract}
Author details
${ }^{1}$ Department of Anaesthesiology, Intensive Care and Pain Therapy, Saarland University Hospital, Kirrberger Straße 100, D-66421 Homburg/Saar, Germany. ${ }^{2}$ Department of Differential Psychology and Psychodiagnostics, Saarland University, Im Stadwald, D-66123 Saarbrücken, Germany. ${ }^{3}$ Department of Internal Medicine V (Integrative Medicine), University of Duisburg-Essen, Kliniken Essen-Mitte, Am Deimelsberg 34a, D-45276 Essen, Germany. ${ }^{4}$ Department of Internal Medicine I, Klinikum Saarbrücken, Winterberg 1, D66119 Saarbrücken, Germany. ${ }^{5}$ Department of Psychosomatic Medicine, Technische Universität München, Ismaninger Straße 22, D-81675 München, Germany.
\end{abstract}

\section{Authors' contributions}

All authors searched the literature, exctracted and analysed the data. All authors had been involved in drafting the manuscript or revising it critically for important intellectual content and gave final approval of the version to be published.

\section{Authors' information}

WH was responsible for the coordination of the German interdisciplinary guideline on the management of fibromyalgia syndrome. He is a trainer in hypnosis. KB and PK were the scientific secretaries of the German guideline group. KB is a licensed psychologist for cognitive-behavioral therapy.

\section{Competing interests}

Dr. Häuser received honoraria for educational lectures by Eli-Lilly, JanssenCilag, Mundipharma and Pfizer and a congress travel grant by Eli-Lilly. Dr. Bernardy received a congress travel grant by Pfizer. The other authors have no competing interests to declare.

Received: 24 November 2010 Accepted: 15 June 2011 Published: 15 June 2011

\section{References}

1. Häuser W, Zimmer C, Felde E, Köllner V: What are the key symptoms of fibromyalgia syndrome? Results of a survey of the German Fibromyalgia Association. In Schmerz. Volume 22. German; 2008:176-183.

2. Mease P, Arnold LM, Choy EH, Clauw DJ, Crofford LJ, Glass JM, Martin SA, Morea J, Simon L, Strand CV, Williams DA, OMERACT Fibromyalgia Working Group: Fibromyalgia syndrome module at OMERACT 9: Domain construct. J Rheumatol 2009, 36(10):2318-29.

3. Berger A, Dukes E, Martin S, Edelsberg J, Oster G: Characteristics and healthcare costs of patients with fibromyalgia syndrome. Int I Clin Pract 2007, 61:1498-508.

4. Jensen MP: Hypnosis for chronic pain management: a new hope. Pain 2009, 146(3):235-7

5. Bennett RM, Jones J, Turk DC, Russell IJ, Matallana L: An internet survey of 2,596 people with fibromyalgia. BMC Musculoskelet Disord 2007, 8:27.

6. Green JP, Barabasz AF, Barrett D, Montgomery GH: Forging ahead. The 2003 APA Definition of hypnosis. Int J Clin Exp Hypn 2005, 53(3):259-64.

7. Menzies $V$, Taylor AG: The idea of imagination: A concept analysis of imagery. ADV. J Mind-Body Med 2004, 20:4-10.

8. Stoelb BL, Molton IR, Jensen MP, Patterson DR: The efficacy of hypnotic analgesia in adults: A review of the literature. Contemp Hypn 2009, 26(1):24-39.

9. Glombiewski JA, Sawyer AT, Gutermann J, Koenig K, Rief W, Hofmann SG: Psychological treatments for fibromyalgia: a meta-analysis. Pain 2010, 151(2):280-95

10. Moher D, Liberati A, Teztlaff J, Altman G, PRISMA Group: Preferred Reporting Items for Systematic Reviews and Meta-Analyses: The PRISMA Statement. Ann Int Med 2009, 51:1-7.

11. Higgins JPT, Green S: Cochrane Handbook for systematic reviews of intervention. Version 5.1.0 [http://www.cochrane-handbook.org/].

12. Bernardy K, Füber N, Köllner V, Häuser W: Efficacy of cognitive behavorial therapies in fibromyalgie syndrome - a systematic review with metaanalyis. J Rheumatol 2010, 37:1991-2005.

13. Yates SL, Morley S, Eccleston E, Williams A: A scale for rating the quality of psychological trials for pain. Pain 2005, 117:314-25.

14. The Nordic Cochrane Centre: Review Manager (RevMan) [Computer program]. Version 5.0 for Windows Copenhagen: The Cochrane Collaboration; 2009.

15. Laird NM, Mostellier F: Some statistical methods for combining experimental results. J Technol Assess Health Care 1990, 6:5-30.

16. Cohen J: Statistical power analysis for the behavoral sciences. Hillsdale: Lawrence Erlbaum Associates; 1988.

17. Egger M, Smith GD, Schneider M, Minder C: Bias in meta-analysis detected by a simple, graphical test. BMJ 1997, 315:629-34.

18. Biostat: Comprehensive metaanalysis software. Version 2.0. Englewood [http://www.metaanalysis.com].

19. Fors EA, Götestam KG: Patient education, guided imagery and pain related talk in fibromyalgia coping. Eur J Psychiat 2000, 14:233-240.

20. Fors EA, Sexton H, Götestam KG: The effect of guided imagery and amitriptyline on daily fibromyalgia pain: a prospective, randomized, controlled trial. J Psychiatr Res 2002, 36(3):179-87.

21. Castel A, Pérez M, Sala J, Padrol A, Rull M: Effect of hypnotic suggestion on fibromyalgic pain: comparison between hypnosis and relaxation. Eur $J$ Pain 2007, 11(4):463-8.

22. Martínez-Valero C, Castel A, Capafons A, Sala J, Espejo B, Cardeña E: Hypnotic treatment synergizes the psychological treatment of fibromyalgia: a pilot study. Am J Clin Hypn 2008, 50(4):311-21.

23. Alvarez-Nemegyei J, Negreros-Castillo A, Nuño-Gutiérrez BL, AlvarezBerzunza J, Alcocer-Martínez LM: [Ericksonian hypnosis in women with fibromyalgia syndrome]. In Rev Med Inst Mex Seguro Soc. Volume 45. Spanish; 2007:(4):395-401 
24. Castel A, Salvat M, Sala J, Rul M: Cognitive-behavioural group treatment with hypnosis: a randomized pilot trail in fibromyalgia. Contemp Hypnosis 2009, 26(1):48-59.

25. Grøndahl JR, Rosvold EO: Hypnosis as a treatment of chronic widespread pain in general practice: a randomised controlled pilot trial. BMC Musculoskelet Disord 2008, 9:124.

26. Haanen HC, Hoenderdos HT, van Romunde LK, Hop WC, Mallee C, Terwiel JP, Hekster GB: Controlled trial of hypnotherapy in the treatment of refractory fibromyalgia. J Rheumatol 1991, 18(1):72-5.

27. Menzies $V$, Taylor AG, Bourguignon C: Effects of guided imagery on outcomes of pain, functional status, and self-efficacy in persons diagnosed with fibromyalgia. J Altern Complement Med 2006, 12(1):23-30

28. Rucco V, Feruglio C, Genco F, Mosanghini R: [Autogenic training versus Erickson's analogical technique in treatment of fibromyalgia syndrome]. In Riv Eur Sci Med Farmacol. Volume 17. Italian; 1995:(1):41-50.

29. Wolfe F, Smythe HA, Yunus MB, Bennett RM, Bombardier C, Goldenberg DL, Tugwell P, Campbell SM, Abeles M, Clark P, et al: The American College of Rheumatology 1990 Criteria for the Classification of Fibromyalgia. Report of the Multicenter Criteria Committee. Arthritis Rheum 1990, 33:160-72.

30. Smythe HA, Moldofsky $H$ : Two contributions to understanding of the "fibrositis" syndrome. Bull Rheum Dis 1977, 28(1):928-31.

31. Thieme K, Häuser W, Batra A, Bernardy K, Felde E, Gesmann M, Illhardt A, Settan M, Wörz R, Köllner V: [Psychotherapy in patients with fibromyalgia syndrome]. In Schmerz. Volume 22. German; 2008:295-302.

32. Thieme K, Gracely RH: Are psychological treatments effective for fibromyalgia pain? Curr Rheumatol Rep 2009, 11(6):443-50.

33. Eccleston C, Williams ACDC, Morley S: Psychological therapies for the management of chronic pain (excluding headache) in adults. Cochrane Database of Systematic Reviews 2009, , 2: CD007407.

34. Dworkin RH, Turk DC, Wyrwich KW, Beaton D, Cleeland CS, Farrar JT, Haythornthwaite JA, Jensen MP, Kerns RD, Ader DN, Brandenburg N, Burke LB, Cella D, Chandler J, Cowan P, Dimitrova R, Dionne R, Hertz S, Jadad AR, Katz NP, Kehlet H, Kramer LD, Manning DC, McCormick C, McDermott MP, McQuay HJ, Patel S, Porter L, Quessy S, Rappaport BA Rauschkolb C, Revicki DA, Rothman M, Schmader KE, Stacey BR, Stauffer JW, von Stein T, White RE, Witter J, Zavisic S: Interpreting the clinical importance of treatment outcomes in chronic pain clinical trials: IMMPACT recommendations. J Pain 2008, 9:105-21.

\section{Pre-publication history}

The pre-publication history for this paper can be accessed here: http://www.biomedcentral.com/1471-2474/12/133/prepub

\section{Submit your next manuscript to BioMed Central and take full advantage of:}

- Convenient online submission

- Thorough peer review

- No space constraints or color figure charges

- Immediate publication on acceptance

- Inclusion in PubMed, CAS, Scopus and Google Scholar

- Research which is freely available for redistribution

Submit your manuscript at www.biomedcentral.com/submit
Biomed Central 